\title{
Radioxenon Standards used in laboratory inter-comparisons
}

H. Gohla*1, M. Auer*, Ph. Cassette**, R. K. Hague***, M. Lechermann****, B. Nadalut*

*CTBTO Preparatory Commission, **Laboratoire National Henri Becquerel, ***Idaho National Laboratory, ****Seibersdorf Laboratories

\begin{abstract}
Preparation methods for ${ }^{133} \mathrm{Xe}$ standards of activity concentration and the results of the $2014{ }^{133} \mathrm{Xe}$ laboratory inter-comparison exercise are described. One element of the quality assurance/quality control (QA/QC) program for laboratories of the International Monitoring System (IMS) will be regular inter-comparison exercises. However, until recently, no activity concentration standards for benchmarking were available. Therefore, two ${ }^{133} \mathrm{Xe}$ activity concentration reference standards were produced independently by Idaho National Laboratory and Seibersdorf Laboratories and used for the 2014 laboratory inter-comparison exercise. The preparation of a complementary ${ }^{127} \mathrm{Xe}$ activity concentration standard as well as a ${ }^{127} \mathrm{Xe}$ laboratory inter-comparison exercise suggests ${ }^{127} \mathrm{Xe}$ as a suitable isotope for QA/QC of remote IMS noble gas stations.
\end{abstract}

Keywords: Comprehensive Nuclear-Test-Ban Treaty (CTBT), International Monitoring System (IMS), noble gas, radioxenon standards, QA/QC program, environmental monitoring, ${ }^{131 \mathrm{~m}} \mathrm{Xe},{ }^{133} \mathrm{Xe},{ }^{133 \mathrm{~m}} \mathrm{Xe},{ }^{135} \mathrm{Xe},{ }^{127} \mathrm{Xe}$

\footnotetext{
${ }^{1}$ Corresponding author: herbert.gohla@ctbto.org
} 


\section{Introduction}

As part of the verification for Comprehensive Nuclear - Test - Ban Treaty (CTBT) compliance, the Provisional Technical Secretariat (PTS) of the CTBTO Preparatory Commission, together with Member States, is establishing an international monitoring network. When completed, the International Monitoring System (IMS) will consist of 321 monitoring stations comprised of four technologies: seismic, infrasound, hydroacoustic and radionuclide monitoring. The radionuclide component of the IMS will consist of 80 radionuclide stations, of which 63 have already been installed and are certified according to IMS station requirements [CTBT/PTS/INF.58/Rev.8, 2007]. All radionuclide monitoring stations will be equipped with air samplers and high purity germanium detectors to detect and measure aerosol borne (particulate) radionuclides. The network of radionuclide stations is supported by 16 laboratories, certified according to IMS radionuclide laboratories requirements, for quality assurance and corroboration of station results. [CTBT/PTS/INF.96/Rev.9].

Particularly for the detection of underground or underwater nuclear explosions, at least forty of the eighty radionuclide stations will also be equipped with systems to measure the radioactive noble gas isotopes ${ }^{131 \mathrm{~m}} \mathrm{Xe}\left(T_{1 / 2}=11.962(20) \mathrm{d}\right),{ }^{133} \mathrm{Xe}\left(T_{1 / 2}=\right.$ $5.2474(5) \mathrm{d}),{ }^{133 \mathrm{~m}} \mathrm{Xe}\left(T_{1 / 2}=2.198(13) \mathrm{d}\right)$ and ${ }^{135} \mathrm{Xe}\left(T_{1 / 2}=9.14(2) \mathrm{h}\right)$. All nuclear data was taken from the DDEP project (http://www.nucleide.org/DDEP_WG/DDEPdata.htm). These are among the radioisotopes with the highest yields in fission of uranium or plutonium. In underground nuclear explosions, noble gases can escape into the atmosphere, while most of the other fission products (the particulates) condense quickly after explosion and are usually trapped in the surroundings of the test cavity [e.g. Carrigan et al., 
1996, De Geer, 1996]. Similarly, in underwater explosions, noble gases have a higher forty noble gas detection systems have been certified according to IMS noble gas station requirements [CTBT/PTS/INF.921/Rev.3, 2008].

\section{Measurement technology}

When the establishment of the IMS radionuclide network commenced in 1997, there was only limited experience with noble gas monitoring and, until the mid-1990s, only laboratory-based manual systems were available. In the course of the IMS development and set-up, automated systems for noble gas monitoring, suitable for operation at remote sites, were developed. In current systems, the sampling process of noble gases is mostly based on the adsorption of xenon on activated charcoal. After sampling, the xenon is desorbed from charcoal by heating and flushing with a carrier gas (either nitrogen or helium), which is further purified with the aim to obtain a sample of xenon and carrier gas only. The determination of xenon activity concentrations in air is done in a two-step procedure - determination of the sampled air volume and of the xenon activity extractable from that volume.

The measurement of the air volume of the sample is done by quantifying the volume of xenon gas in the counting cell. Natural occurring xenon is present in atmospheric air at an abundance of 87 parts per billion by volume (ppbv), as defined in the U.S. Standard Atmosphere [CRC2014]. Therefore, the corresponding air volume of a sample, $V_{\text {air }}$, is determined by $V_{\text {air }}=V_{\text {Xe }} / 0.087 * 10^{-6}$, where $V_{\mathrm{Xe}}$ is the volume of xenon in the sample. As a consequence, the activity concentration, $\langle A\rangle$, of a sample is:

$$
<A>=\frac{\text { Sample Activity }[\mathrm{Bq}]}{\text { Xenon Volume }\left[\mathrm{cm}^{3}\right]} * 0.087 \frac{\left[\mathrm{cm}^{3}\right]}{\left[\mathrm{m}^{3}\right]}
$$


The xenon volume measurement is done with a thermal conductivity detector either in a static volume or in a gas chromatograph [Ringbom et al., 2003, Fontaine et al., 2004, Dubasov et al., 2005].

Activity measurements with IMS noble gas (NG) systems are done either by highresolution gamma-ray spectrometry or beta-gamma coincidence counting. One requirement for the NG systems deployed in the IMS is to have a minimum detectable concentration for ${ }^{133} \mathrm{Xe}$ of $\leq 1 \mathrm{mBq} / \mathrm{m}^{3}$ as defined in [CTBT/PTS/INF.921/Rev.3, $2008]$; the total sample air volume is typically $10-75 \mathrm{~m}^{3}$, depending on the type of noble gas system [Auer et al., 2010].

\section{3. $\mathrm{QA} / \mathrm{QC}$ requirements}

To ensure a high quality of data provided by the IMS NG systems, a comprehensive quality assurance/quality control (QA/QC) program needs to be established. One component of such a QA/QC program is the evaluation of station performance through independent measurements of samples from the deployed systems by participating laboratories. For this purpose, either routine ambient air samples or samples "spiked" with radioactive xenon can be used. The actual parameters measured at noble gas stations and by laboratories are the activity of xenon isotopes and the volume of xenon gas in the sample. In general, a perfect match of values measured at the noble gas station and at the laboratory it is not expected, because of a potential loss of gas or dead volumes not accounted for by the noble gas systems.

Xenon activity concentrations and isotope ratios are used as key parameters because they are independent of any gas losses. A deviation of station and lab result of these parameters within $15 \%$ is generally considered acceptable. Samples containing both 
${ }^{131 \mathrm{~m}} \mathrm{Xe}$ and ${ }^{133} \mathrm{Xe}$ are the most suitable, owing to sufficiently long half-lives of these two isotopes to account for the transportation time between stations and laboratories. However, routine re-measurement of ${ }^{133 \mathrm{~m}} \mathrm{Xe}$ is quite challenging, and not feasible for ${ }^{135}$ Xe due to short half-life.

Laboratory measurements are crucial in a QA/QC program. As a consequence, good accuracy and traceability of the actual measurements are also of critical importance in order to provide confidence in the results. Therefore, in order to ensure the credibility of IMS laboratories as providers of reference results, the QA/QC program for laboratories must include regular proficiency test exercises (PTE) to assess the performance of a laboratory against pre-established criteria.

Currently six IMS radionuclide laboratories have noble gas measurement capabilities (using in-house developments and commercially available equipment) for the four CTBT-relevant xenon isotopes $\left({ }^{131 \mathrm{~m}} \mathrm{Xe},{ }^{133} \mathrm{Xe},{ }^{133 \mathrm{~m}} \mathrm{Xe}\right.$ and $\left.{ }^{135} \mathrm{Xe}\right)$ and are able to perform on-request reanalysis of NG samples from the certified IMS NG stations. These laboratories have participated in a QA/QC pilot program for noble gas measurements.

\section{Xenon inter-comparison exercises}

Several laboratory inter-comparison exercises have been conducted since 2008 [Gohla et al., 2011; Gohla and Auer 2013], initially with only four laboratories participating (three IMS laboratories and one non-IMS laboratory). The purpose of these exercises were to assist the laboratories in the development of noble gas measurement capabilities and to eventually establish regular proficiency test exercises as part of the QA/QC program. To that end, nearly identical samples (or one sample split for distribution among the participants) were sent to the participating laboratories by the 
producers. Quality checks (e.g., leak testing of sample containers, xenon homogeneity) were conducted. Sample transport from the producer to the laboratories was usually completed within five days.

Although international comparisons of ${ }^{133} \mathrm{Xe}$ activity standards exist (Ratel and Michotte 2004), no activity concentration standards traceable to the SI were available. Consequently, for previous (2008-2012) inter-comparisons among laboratories, no references were available for benchmarking.

Figure 1 shows a typical result of an inter-comparison exercise of ${ }^{133} \mathrm{Xe}$ activity concentration measurements carried out in 2012. The quantity determined at the laboratories was in units of $\mathrm{Bq} / \mathrm{cm}^{3}$ xenon which, for reporting, was converted to $\mathrm{Bq} / \mathrm{m}^{3}$ air. The results span a range of $\pm 25 \%$ around the midpoint. The variation among results is independent of the sample type (transport bottle, Xe volume, carrier gas) and laboratory measurement system type. Typically, as could be expected, the ratio ${ }^{131 \mathrm{~m}} \mathrm{Xe} /{ }^{133} \mathrm{Xe}$ results show a better agreement than activity concentrations; the deviation from the mean of ratio results is typically within $10 \%$ [Gohla and Auer, 2013].

\section{Development of ${ }^{133} \mathrm{Xe}$ activity concentration standards}

Traceable radioxenon activity standards with moderate activities ( $\mathrm{kBq}$ range) were already available from several suppliers (e.g., Eckert \& Ziegler), but the highefficiency detection systems involved in atmospheric radioxenon monitoring are unable to process activity levels that are typical for these gas standards. For the purpose of the IMS QA/QC program, radioxenon activity concentration standards (activity of a specific Xe radioisotope per volume of total xenon in $\mathrm{Bq} / \mathrm{cm}^{3}$ ) are needed. Therefore, the development of such standards has become a high priority in 
the advancement of the noble gas measurement capabilities of the laboratories and the QA/QC program in general. Although such standards may also be used for equipment calibration, they are expected to be used primarily as reference samples for laboratory inter-comparisons. Two independent reference standards for ${ }^{133} \mathrm{Xe}$ activity concentration have been produced recently by the US Department of Energy Idaho National Laboratory (INL, P.O. Box 1625, Idaho Falls, Idaho 83415-3520, United States of America) and the State-held Seibersdorf Laboratories (SL, A-2444 Seibersdorf, Austria) and are described in this section.

$\underline{\text { Idaho National Laboratory }{ }^{133} \mathrm{Xe} \text { activity concentration standard. }}$

The Idaho National Laboratory supplies ${ }^{133} \mathrm{Xe}$ activity concentration standards that are validated using a detector calibrated with 6 U.S. National Institute of Standards and Technology (NIST) standards as shown in Figure 2.

Corrections to ${ }^{133} \mathrm{Xe}$ activity were applied to the NIST standards as a function of xenon self-attenuation and accounting for the xenon that decayed to Cs and no longer contributed to attenuation. Quality assurance checks on the detector were performed using an SRS 85580-370 mixed-gamma source purchased from Eckert \& Ziegler. A radio-pharmaceutical supply of 25 milliCurie $(0.925 \mathrm{GBq}){ }^{133} \mathrm{Xe}$ is routinely purchased by INL from Advanced Isotopes (Chuback, Idaho). The ${ }^{133} \mathrm{Xe}$ and ${ }^{133 \mathrm{~m}} \mathrm{Xe}$ (if any is left after substantial decay) mixture, as purchased, is slowly introduced into a mass separator. The ${ }^{133} \mathrm{Xe}$ and ${ }^{133 \mathrm{~m}} \mathrm{Xe}$, with some small tailing of the stable ${ }^{132} \mathrm{Xe}$ and ${ }^{134} \mathrm{Xe}$, are isolated from the fission xenon mixture and implanted onto a small piece of aluminium foil located on the collection target of the mass separator as described in [Carney et al., 2013]. The ${ }^{133} \mathrm{Xe}$-loaded aluminium foil is removed from 
the mass separator and sent to the noble gas laboratory for preliminary analysis by gamma-ray spectrometry.

The separated product is released from its implanted position in aluminium foil by the melting of the foil while the sample is held in a quartz vial containing a wellcharacterized $\sim 0.5 \mathrm{~cm}^{3}$ to $1.0 \mathrm{~cm}^{3}$ natural xenon gas as carrier.

The INL assays the ${ }^{133} \mathrm{Xe}$-enriched gas by isolating a desired amount of ${ }^{133} \mathrm{Xe}$ in xenon carrier and performing a comparator calibration of the material using a gammaray spectrometer. The aliquot of ${ }^{133} \mathrm{Xe}$ in carrier is then further diluted with natural xenon carrier and mixed to achieve the desired activity concentration. This gas mixture was referred to as the "working gas." Five $1.0 \mathrm{~cm}^{3}$ fractions of the working gas are then sealed in separate glass ampoules for verification of leaks and homogeneity, to provide assay comparators throughout the filling process. An example is provided below in Table 1 . Aliquots of $1 \mathrm{~cm}^{3}$ are then placed in the desired number of gas bottles and further diluted with $350 \mathrm{~cm}^{3}$ of helium. A further sample containing $1 \mathrm{~cm}^{3}$ of the mother ${ }^{133} \mathrm{Xe}$ solution is drawn, and both calibration and homogeneity checked at the beginning and end of each day the gas bottles are filled to verify that no contaminants have entered the solution.

All natural xenon carriers are at least $99.999 \%$ pure and are quantified in manifolds with volumes established by a combination of water weighing and expansion. All pressures are measured with manometers calibrated by their manufacturer every year with traceability to NIST. The INL calculates the uncertainty for their standards in compliance with ISO 17025 and typically have expanded relative uncertainties of $\sim 6$ $\%(k=2)$ [Hague, R. et al., (2015a); Hague, R. et al., (2015b)].

$\underline{\text { Seibersdorf Laboratories }{ }^{133} \text { Xe activity concentration standard }}$ 
The Seibersdorf Laboratories (SL) operates the ISO 17035 accredited radionuclide laboratory ATL03, one of the 16 assigned laboratories within the IMS network. They have built up capabilities in noble gas analysis, such as measurement of atmospheric low-level radioxenon samples. Their method relies on the dilution of a secondary gas standard of ${ }^{133} \mathrm{Xe}$ activity, purchased from Eckert \& Ziegler, by addition of a large amount of pure xenon gas. The added xenon gas is measured gravimetrically by highly accurate and traceable balances. The resulting gas mixture has well-known ${ }^{133} \mathrm{Xe}$ activity and stable xenon content and, thus, a defined activity concentration. As a first step, the radioxenon standard container, typically a glass vial or glass sphere, is verified to be gas-tight by monitoring the activity of the container over a period of several days using a high-purity germanium (HPGe) gamma-ray spectrometer at a well-defined and reproducible geometry. Because of the activity level of the standard, statistical fluctuations in the $81 \mathrm{keV}$ peak areas are smaller than $0.5 \%$.

Having ensured the gas-tightness of the container as a precondition, the gas standard is then transferred into an aluminium cylinder with well-known volume [Lecherman et al., 2014]. The transfer of the standard is performed by flushing the original standard container through with pressurized dry air directly into the cylinder. The empty standard container is then analysed with an HPGe gamma-ray spectrometer to determine residual activity since greased valves or septa are known to trap xenon. Typically, the residual activity is less than $0.01 \%$ of the total activity.

Weighing the aluminium cylinder before and after adding pure xenon gas allows the exact determination of stable xenon content. The high atomic mass of xenon facilitates accurate gravimetric measurements allowing the determination of a well- 
known activity concentration of ${ }^{133}$ Xe per xenon volume $\left[\mathrm{Bq} / \mathrm{cm}^{3}\right]$ contained in the ${ }^{133} \mathrm{Xe}$ "mother" dilution.

The total uncertainty of the activity concentration standard consists mainly of the uncertainty of the activity standard and the uncertainty of the stable xenon measurement. Typical expanded relative uncertainties $(k=2)$ of ${ }^{133} \mathrm{Xe}$ activities in secondary gas standards, as reported by Eckert \& Ziegler, range from $3.5 \%$ to $3.8 \%$. Depending on the total amount of stable xenon, expanded relative uncertainties of stable xenon content range from $1.2 \%$ to $2.4 \%$. Thus, ${ }^{133} \mathrm{Xe}$ activity concentration reference gases have expanded relative uncertainties of from $3.7 \%$ to $4.4 \%$.

The desired amount of ${ }^{133} \mathrm{Xe}$ "mother" dilution is drawn off and split among 20 gastight bottles by using different manifolds. Gas-tightness is verified in prior quality checks of each gas bottle. While the total amount of reference gas that has been drawn off is not precisely known, the activity concentration remains well-defined. The gas bottles are then filled up with helium or nitrogen to the desired pressures typical for the different NG systems.

All gases involved in the preparation have at least $99.999 \%$ purity, and the gas suppliers certify measurement traceability to the SI. All balances involved are calibrated and traceable to the SI.

\section{Laboratory Inter-comparison with ${ }^{133} \mathrm{Xe}$ activity concentration reference standards}

A laboratory inter-comparison exercise, using a ${ }^{133} \mathrm{Xe}$ activity concentration reference standard produced by the SL, was conducted for the first time in 2013 (unpublished). 
This standard provided a benchmark for laboratories and led to enhancements at resulted in an improved agreement among laboratory measurements and the reference values. In 2014, the laboratory inter-comparison exercise was conducted with two independently produced standards from both INL and SL. Two samples from the reference standard were provided by INL to participants (for logistical reasons, not all participants received all samples). All the samples had identical (within stated uncertainties $){ }^{133} \mathrm{Xe}$ activity concentrations $\left[(0.174 \pm 0.005) \mathrm{Bq} / \mathrm{cm}^{3}\right.$ under standard temperature and pressure conditions (STP) of ${ }^{133} \mathrm{Xe}$ in air equivalent] [Hague, R. et al., (2015a)]. SL produced two reference standards and provided one sample of each reference standard to participants; all samples of each standard had identical (within stated uncertainties) ${ }^{133} \mathrm{Xe}$ activity concentrations: $\left[(0.177 \pm 0.004) \mathrm{Bq} / \mathrm{cm}^{3}\right.$ STP of ${ }^{133} \mathrm{Xe}$ in air equivalent; $(0.087 \pm 0.002) \mathrm{Bq} / \mathrm{cm}^{3} \mathrm{STP}$ of ${ }^{133} \mathrm{Xe}$ in air equivalent $\left.)\right]$ [Lecherman et al., 2014]. The activity concentration levels of the reference standards from INL and SL were well above the typical laboratory detection limits for ${ }^{133} \mathrm{Xe}$; uncertainties of the reference values were $3.0 \%$ (INL) and $2.1 \%$ (SL), respectively $(k=1)$. Ten laboratories participated in this inter-comparison exercise as shown in Table 2, wherein the first six in the list are IMS laboratories.

Figure 3 shows the percentage deviation of laboratory measurements from the ${ }^{133} \mathrm{Xe}$ activity concentrations values by the providers of the reference standards. Reported uncertainties are combined uncertainties of the standards and laboratory results $(k=1)$. Those laboratories that run two independent noble gas measurement systems are indicated with a letter next to the laboratory number (e.g., 6a, 6b) in Fig. 3. The laboratory measurements were coherent with both standards. 
Table 3 shows the difference between the bias of the INL and the SL standards, respectively, to laboratory measurements. The average difference between the bias with the INL standard compared to that with the SL standard is $0.3 \%$ with a standard deviation of $5.1 \%$. A comparison of the laboratory results for the two standards indicates a very good agreement between them.

\section{Rationale for $\mathbf{a}^{127} \mathrm{Xe}$ standard}

The remoteness of some IMS stations makes the use of ${ }^{131 \mathrm{~m}} \mathrm{Xe}$ and ${ }^{133} \mathrm{Xe}$ isotopes for the QA/QC program very challenging, due to their short half-life compared to shipping times. Therefore, ${ }^{127} \mathrm{Xe}$ has been suggested as a possible candidate for spiking at remote noble gas stations. Even though ${ }^{127} \mathrm{Xe}$ is not a relevant radionuclide for the CTBT, it can be used for QA/QC of remote IMS NG measurement systems due to its rather long half-life $\left(T_{1 / 2}=36.358(31) \mathrm{d}\right)$ [http://www.nucleide.org/DDEP_WG/Nuclides/Xe-127_tables.pdf ] compared to the other xenon isotopes. Xenon-127 decays by electron capture to excited levels of ${ }^{127} \mathrm{I}$ with a cascade of 5 main gamma ray emissions in the 57.6 to $375.0 \mathrm{keV}$ energy range, followed by the characteristic $\mathrm{x}$ rays of iodine due to the atomic rearrangements after the electron capture and the gamma de-excitation. With technical and scientific support of the LNHB (Laboratoire National Henri Becquerel - CEA LIST, Saclay, France) and of the IMS Radionuclide Laboratory FRL08 (CEA/DASE, Bruyères-leChâtel, France) during 2011, the PTS conducted a feasibility study (unpublished) on the potential use of ${ }^{127} \mathrm{Xe}$. Two different tests were performed: (a) an intercomparison of IMS labs using a set of test samples spiked at some designated IMS NG systems, and (b) a preliminary evaluation on the possible use of ${ }^{127} \mathrm{Xe}$ with photon-electron detector systems. Conclusions from the study showed that ${ }^{127} \mathrm{Xe}$ can 
be considered useful for the many checks foreseen within the QA/QC program for noble gas monitoring systems in use at IMS stations, but is quite complicated for efficiency calibration checks of $\beta / \gamma$ coincidence systems, as described previously (Cagniant et al., 2014).

\section{Development of a ${ }^{127} \mathrm{Xe}$ activity concentration standard}

The ${ }^{127}$ Xe source was supplied by a commercial provider. The sample was composed of xenon in nitrogen and contained ${ }^{125} \mathrm{I}$ as a radioactive impurity. This impurity was completely removed by the use of a filter made of silver wool, and the final radioactive purity was checked by gamma-ray spectrometry. Xe-127 was standardized at LNE-LNHB, the National Metrology Institute of France for ionizing radiations, by internal gas counting (Lansiart et al., 1993) using three proportional detectors with different lengths. The calibration method is described by (Rodrigues et al., 2014). The activity per unit volume under standard temperature and pressure conditions (STP) was: $452.1(3.1) \mathrm{Bq} / \mathrm{cm}^{3}$ at the reference date of 29/12/2013, $12 \mathrm{~h} 00 \mathrm{UTC}$. The relative standard uncertainty components include the counting statistics $(0.38 \%)$, the counter volumes $(0.23 \%)$, the reference volume of the gas sample and its STP correction $(0.3 \%)$, the decay corrections to the reference date and the decay correction during the measurement $(0.05 \%)$, the counting uncertainty due to the discriminator threshold adjustments $(0.15 \%)$ and the uncertainty on the detection efficiency $(0.4 \%)$. This reference activity was used to prepare diluted standards which were used for the comparison.

Complementary measurements were performed using a $5 \mathrm{~cm}^{3}$ glass vial that allowed the $\mathrm{x}$ rays to exit from the container and to be registered in the detector. This measurement was also used to check the impurities of ${ }^{125} \mathrm{I}$ and ${ }^{129} \mathrm{I}$. In their decay, 
both radionuclides emit low energy gamma-rays, respectively $35.49 \mathrm{keV}$ and $39.58 \mathrm{keV}$, close to the $\mathrm{K} \mathrm{x}$-ray lines of iodine resulting from the ${ }^{127} \mathrm{Xe}$ decay. In this measurement, the detection limit for both radionuclides relative to the ${ }^{127} \mathrm{Xe}$ activity was $5 \times 10^{-3}$.

\section{Laboratory inter-comparison with the ${ }^{127} \mathrm{Xe}$ standard}

Four IMS radionuclide laboratories participated in a test inter-comparison organized by the CTBTO in 2011 and based on certified gaseous standard sources of ${ }^{127} \mathrm{Xe}$ in nitrogen prepared as described in Cagniant et al., 2014. Four gas bottles were filled from the same master source, at the same pressure and temperature, with ${ }^{127} \mathrm{Xe}$ activity concentration $\left[(0.188 \pm 0.006) \mathrm{Bq} / \mathrm{cm}^{3} \mathrm{STP}\right.$ of ${ }^{127} \mathrm{Xe}$ and no stable xenon $]$ and delivered to the laboratories participating in the inter-comparison. A reference value of $50.8(22) \mathrm{Bq}(4.3 \%, k=1)$ was also provided for the total activity of the samples. Results are shown in Fig. 4.

Lab.1 added some stable xenon to the sample, and provided two different results: Lab.1a values calculated in the assumption of no loss of sample due to stable xenon addition, and Lab.1b results on the assumption of partial sample loss from the addition of stable xenon. The biased result at Lab.2 triggered a corrective action at the laboratory once the reasons for the bias were identified. This was the first case of a xenon intercomparison organized by the CTBTO with known reference values for activities. The participating laboratories used HPGe detection systems or proportional counters and the results indicate that ${ }^{127} \mathrm{Xe}$ can be correctly quantified by CTBT laboratories and therefore remeasurement of ${ }^{127} \mathrm{Xe}$ samples at laboratories can be used for QA/QC checks of IMS stations using HPGe detectors. The four laboratories demonstrated the capability to quantify ${ }^{127}$ Xe activity values. 


\section{Conclusions}

The development of two independent ${ }^{133} \mathrm{Xe}$ activity concentration standards has been a big step forward in the establishment of a QA/QC program for the IMS noble gas station network. Comparison of the two standards by use of laboratory results indicates a very good agreement of the two standards. Xe-127 also seems to be a suitable isotope for QA/QC of remote IMS noble gas stations.

\section{Acknowledgements}

The authors wish to thank ATL03 (Seibersdorf Laboratories, Austria), CAL05 (Radiation Protection Bureau, Health Canada, Ottawa, Canada), CNL06 (Beijing Radionuclide Laboratory, China), FRL08 (Commissariat à l’Énergie Atomique, France), GBL15 (Atomic Weapons Establishment, United Kingdom), USL16 (US Department of Energy Pacific Northwest National Laboratory, United States of America), BfS (Bundesamt für Strahlenschutz, Freiburg, Germany), FOI (Swedish Defence Research Agency, Stockholm, Sweden), ENEA (Italian National Agency for New Technologies, Bologna, Italy) and IRL (Department of Energy and Physics, Amirkabir University of Technology, Teheran, Iran) for the participation in the intercomparison exercises. 


\section{References}

Auer, M., Kumberg, T., Satorius, H., Wernsperger, B., Schlosser, C., (2010) Ten Years of Development of Equipment for Measurement of Atmospheric Radioactive Xenon for the Verification of the CTBT, Pure Appl. Geophys. 167, $471-486$

Cagniant, A., Le Petit, G., Nadalut, B., Gross, P., Richard-Bressand, H., Fontaine, J.P., Douysset, G. (2014) On the use of ${ }^{127}$ Xe standards for the quality control of CTBTO noble gas stations and support laboratories, Applied radiation and isotopes, $89,176-185$

Carney, K. P., Horkley, J. J., McGrath, C. A., Edwards, A. J., Davies, J. E., Knighton, G. C., Sommers, J. D., Giglio, J. J. (2013) Advancement in isotope separation for production of reference standards. J. of Radioanalytical and Nuclear Chemistry (2013) 296:383-387 DOI 10.1007/s10967-012-2149-4

Carrigan, C.R., Heinle, R.A., Hudson, G.B., Nitao, J.J., Zucca, J.J. (1996) Trace gas emissions on geological faults as indicators of underground nuclear testing, Nature 382, 528-531.

CRC2014 (2014) CRC Handbook of Chemistry and Physics $95^{\text {th }}$ edition

CTBT/PTS/INF.58/Rev.8 (2007) Certification of IMS particulate radionuclide stations (with guidelines for station installation)

CTBT/PTS/INF.921/Rev.3 (2008) Certification of noble gas equipment at IMS radionuclide stations (with guidelines for station installation)

CTBT/PTS/INF.96/Rev.9 (2012) Certification and surveillance assessment of radionuclide laboratories for particulate and noble gas sample analysis

De Geer, L.-E., (1996) Sniffing out clandestine tests, Nature 382, 107. 
Dubasov, Y. V., Popov, Y. S., Prelovskii, V. V., Donets, A. Y., Kazarinov, N. M., Mishurinskii, V. V., Popov, V. Y., Rykov, Y. M., Skirda, N. V., (2005) The APIKC-01 automatic facility for measuring concentrations of radioactive xenon isotopes in the atmosphere, Instruments and Experimental Techniques 48, 373379.

Fontaine, J. P., Pointurier, F., Blanchard, X., Taffary, T., (2004) Atmospheric xenon radioactive isotope monitoring, J. of Environmental Radioactivity 72, 129-135.

Gohla, H., Auer, M., Schlosser, C., (2011) Re-analysis of noble gas samples from IMS stations at laboratories - a review of the results since 2007, poster at Science and Technology conference 2011, Vienna, Austria

Gohla, H., Auer, M., (2013) Results of Xenon Laboratory Intercomparison Exercises Performed in 2012, poster at Science and Technology conference 2013, Vienna, Austria

Hague, R. K., Houghton T., Robinson T., Watrous, M. (2015a) CTBTO 4-3-2014

(Rev 1) Sample Production Report, personal communication

Hague, R. K., Houghton T., Robinson T., Watrous M., (2015b) CTBTO 23 MAR 2015 Sample Production Report, personal communication

Lansiart, A., Dhilly, G., Picolo, J. L., (1993). Note Technique LPRI/93/010.

Lecherman, M., Schroettner, Th., (2014) Production of Traceable Radioxenon Concentration Standard, personal communication

Nadalut, B., Le Petit, G., Gheddou, A., Cagniant, A., Gohla, H., Wernsperger, B., (2013) Use of Xe-127 in Quality Assurance of IMS Noble Gas Systems, presented at INGE Workshop 2013, Vienna

Nadalut, B., Gohla, H., Wernsperger, B., Schlosser, C., Lechermann, M., Le Petit, G., Wang, S., Bean, M., Aldener, M., (2013) Testing use of Xe127 in QAQC 
program for NG, presented at CTBT Radionuclide Laboratory Workshop, Jerusalem, 2013

Ratel, G., Michotte, C., (2004) BIPM comparison BIPM.RI(II)-K1.Xe-133 of activity measurements of the radionuclide ${ }^{133} \mathrm{Xe}$, Metrologia 41 Tech. Suppl. 06011.

Ringbom, A., Larson, T., Axelsson, A., Elmgren, K., Johansson, C., (2003)

SAUNA - A system for automatic sampling, processing, and analysis of radioactive xenon, Nuclear Instruments and Methods in Physics Research Section A, 508, 542-553.

Rodrigues, M., Lépy, M. C., Cassette, P., Mougeot, X., Bé, M. M., (2014)

Standardization of xenon -127 and measurement of photon emission intensities. Applied Radiation and Isotopes, 87, 342-347.

\section{Figure captions:}

Fig. 1. ${ }^{133} \mathrm{Xe}$ activity concentration results of an inter-comparison exercise in 2012. Uncertainties are shown for $k=1$

Fig. 2. Measured Efficiencies for ${ }^{133} \mathrm{Xe}$ as obtained using the conventional calibration method. Error bars reflect $2 \sigma$ uncertainty. Number of replicates efficiency determinations by year: [2010 n=8]; [2011 aliquot\#1 n=3]; [2011 Aliquot\#2 $\mathrm{n}=3$ ]; [2012 Aliquot\#1 n=10]; [2012 Aliquot\#2 n=10]; [2014 n=3].

Fig. 3. Percentage deviation of laboratory measurements from the reference values of two ${ }^{133} \mathrm{Xe}$ activity concentration standards and corresponding uncertainty $(k=$ 1). The results are from an inter-comparison exercise in 2014. Vertical dashed lines separate values of different laboratories. 
1

2

3

4

5

7

8

9

10

12

13

14

15

16

17

18

19

20

21

22

23

24

25

26

27

28

29

30

31

32

33

34

35

36

37

38

39

40

41

42

43

44

45

46

47

48

49

50

51

52

53

54

55

56

57

58

59

60

61

62

63

64

65

Fig. 4. Results of ${ }^{127}$ Xe laboratory inter-comparison of activity values [in Bq]. 
Table 1: Assay results of the 5 leak-verification samples:

$$
\begin{array}{ll}
\text { Verification \#1 } & { }^{133} \mathrm{Xe}(1.00 \pm 0.03) \mathrm{Bq} / \mathrm{cm}^{3} \\
\text { Verification \#2 } & { }^{133} \mathrm{Xe}(1.01 \pm 0.03) \mathrm{Bq} / \mathrm{cm}^{3} \\
\text { Verification \#3 } & { }^{133} \mathrm{Xe}(1.00 \pm 0.03) \mathrm{Bq} / \mathrm{cm}^{3} \\
\text { Verification \#4 } & { }^{133} \mathrm{Xe}(1.01 \pm 0.03) \mathrm{Bq} / \mathrm{cm}^{3} \\
\text { Verification \#5 } & { }^{133} \mathrm{Xe}(0.99 \pm 0.03) \mathrm{Bq} / \mathrm{cm}^{3}
\end{array}
$$

( $1 \sigma$ uncertainty at $0{ }^{\circ} \mathrm{C}$ and 0.101325 MPa, 23 Mar 2015 12:00 UTC). 
Table 2: Participants of inter-comparison exercise in 2014

Laboratories

ATL03, Seibersdorf Laboratories, Austria

CAL05, Radiation Protection Bureau, Health Canada, Ottawa, Canada

CNL06, Beijing Radionuclide Laboratory, China

FRL08, Commissariat à l’Énergie Atomique, France,

GBL15, Atomic Weapons Establishment, United Kingdom

USL16, US Department of Energy Pacific Northwest National Laboratory, United States of America

BfS, Bundesamt für Strahlenschutz, Freiburg, Germany

FOI, Swedish Defence Research Agency, Stockholm, Sweden

ENEA, Italian National Agency for New Technologies, Bologna, Italy

IRL, Department of Energy and Physics, Amirkabir University of Technology, Teheran, Iran 
Table 3: Difference between the bias of INL reference standard to laboratory measurement and SL reference standard to laboratory measurement for Xe-133 activity concentrations.

\begin{tabular}{cc}
\hline & $\begin{array}{c}\text { \% Difference (lab-INL) - \% Difference } \\
(\text { lab-SL) } \%]\end{array}$ \\
\hline Lab 1 & -1.1 \\
Lab 2 & -2.9 \\
Lab 3 & 10.9 \\
Lab 4 & -5.6 \\
Lab 5 & 0.7 \\
Lab 6a & -3.2 \\
Lab 6b & -0.2 \\
Lab 7 & 3.9 \\
\hline mean & 0.3 \\
\hline
\end{tabular}




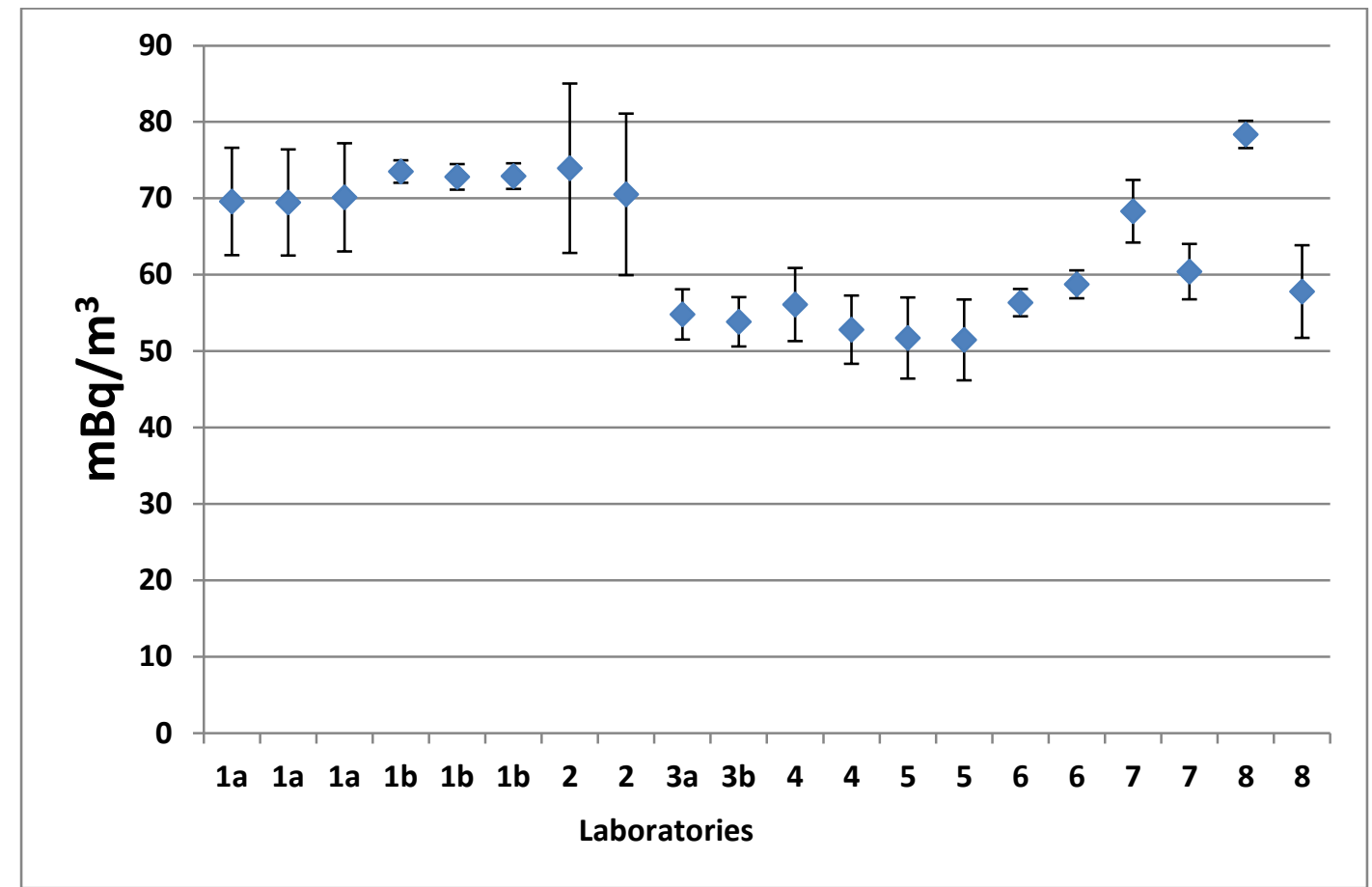

Fig. 1 


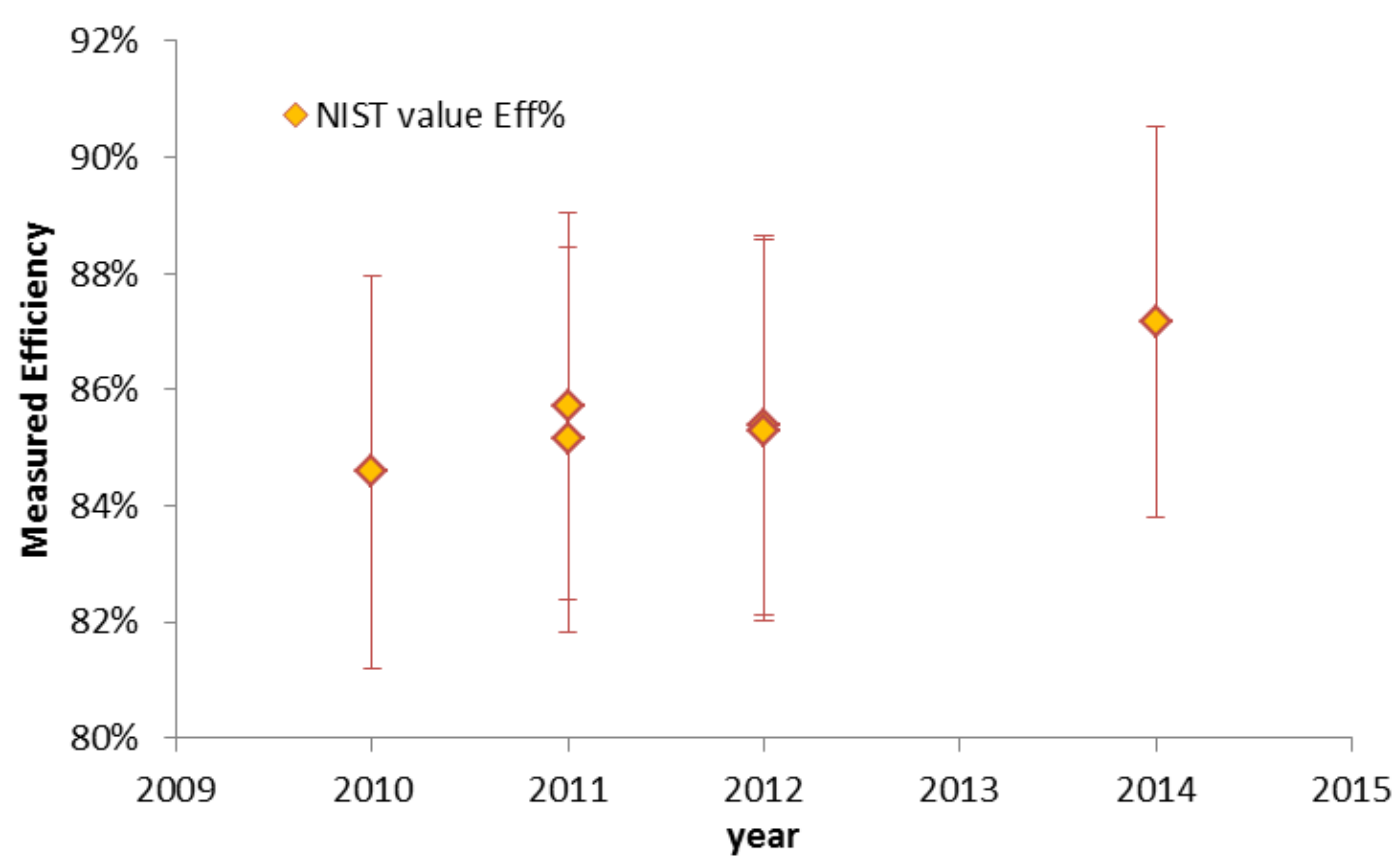

Fig. 2 


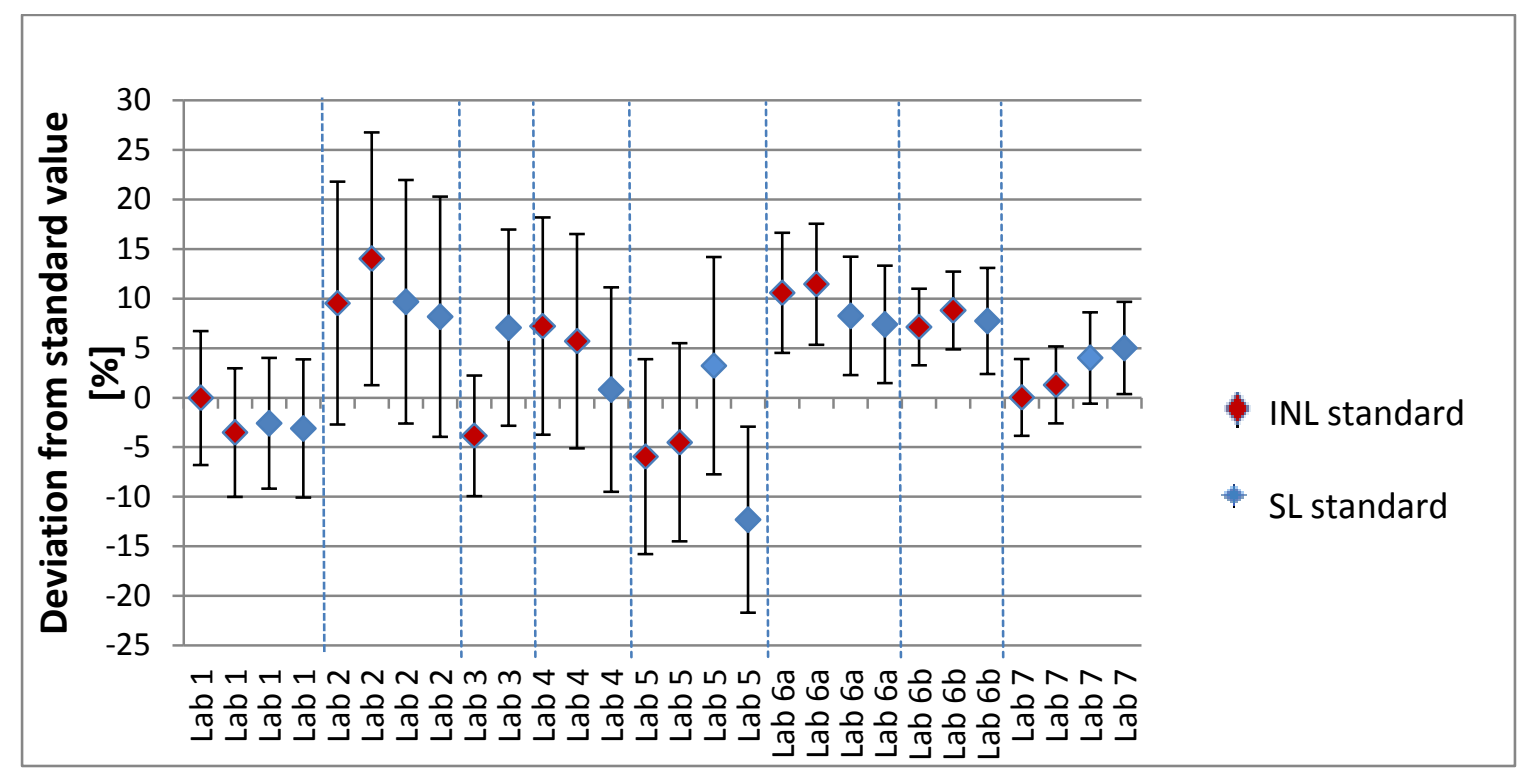

Fig. 3 


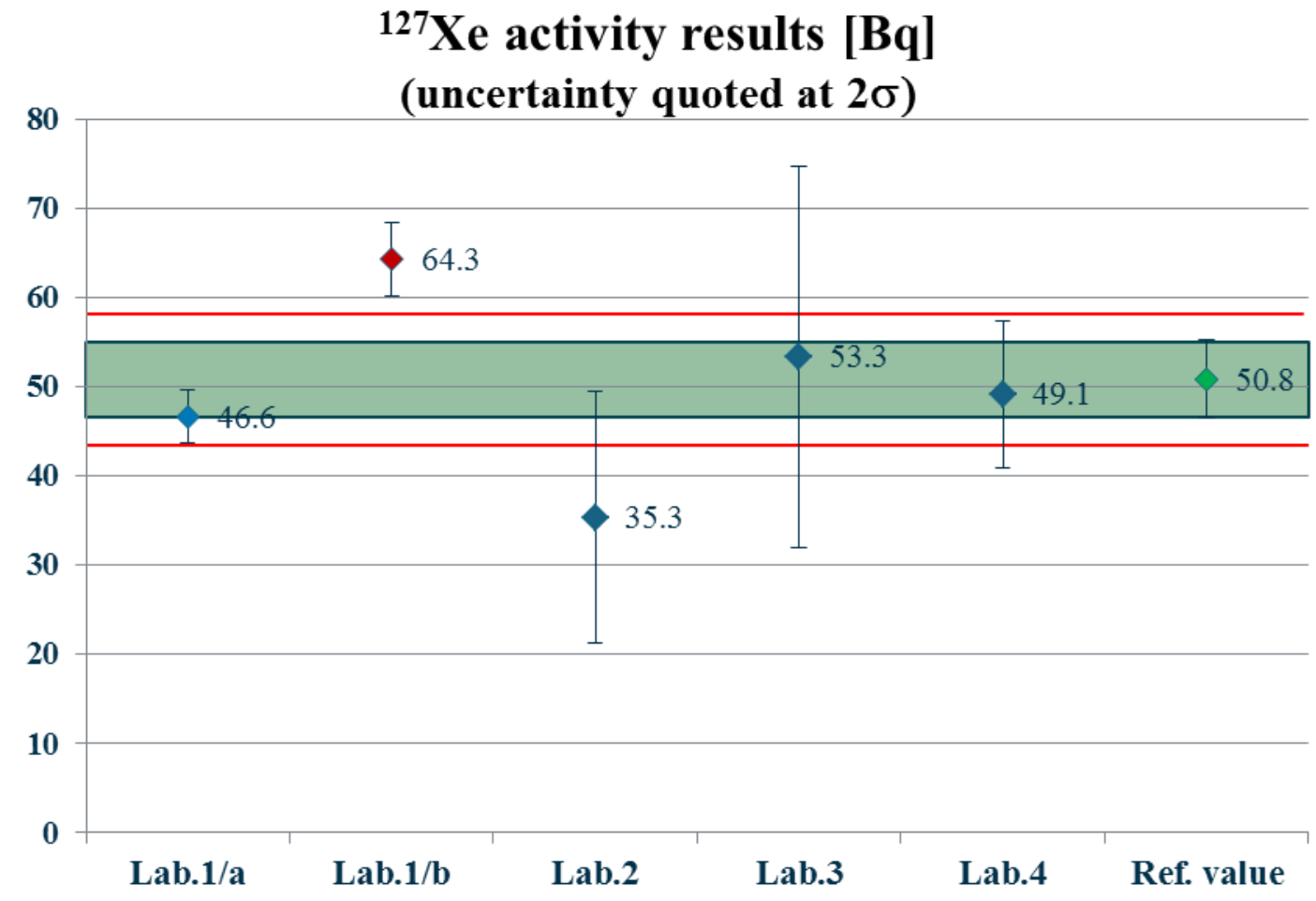

Fig. 4 